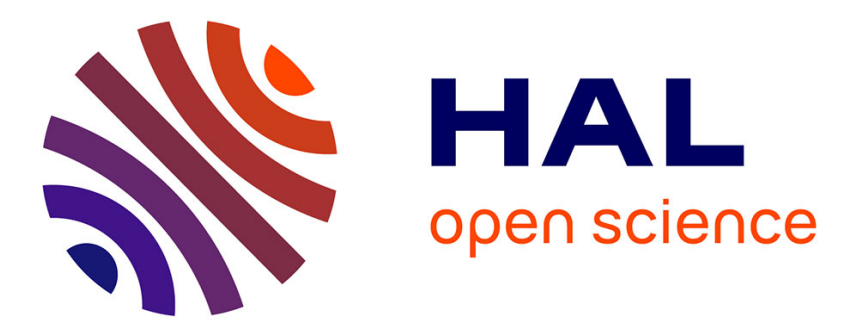

\title{
Detection of swing heel-off event in gait initiation using force-plate data
}

Teddy Caderby, Eric Yiou, Nicolas Peyrot, Bruno Bonazzi, Georges Dalleau

\section{To cite this version:}

Teddy Caderby, Eric Yiou, Nicolas Peyrot, Bruno Bonazzi, Georges Dalleau. Detection of swing heel-off event in gait initiation using force-plate data. Gait \& Posture, 2013, 37 (3), http://dx.doi.org/10.1016/j.gaitpost.2012.08.011. 10.1016/j.gaitpost.2012.08.011 . hal-00811705v2

\section{HAL Id: hal-00811705 \\ https://hal.science/hal-00811705v2}

Submitted on 27 Oct 2016

HAL is a multi-disciplinary open access archive for the deposit and dissemination of scientific research documents, whether they are published or not. The documents may come from teaching and research institutions in France or abroad, or from public or private research centers.
L'archive ouverte pluridisciplinaire HAL, est destinée au dépôt et à la diffusion de documents scientifiques de niveau recherche, publiés ou non, émanant des établissements d'enseignement et de recherche français ou étrangers, des laboratoires publics ou privés. 


\title{
Short communication
}

\section{Detection of swing heel-off event in gait initiation using force-plate data}

\author{
T. Caderby ${ }^{\text {a,* }}$, E. Yiou ${ }^{\text {b }, ~ N . ~ P e y r o t ~}{ }^{a}$, B. Bonazzi ${ }^{\text {a }}$, G. Dalleau ${ }^{\text {a }}$ \\ a Laboratoire CURAPS-DIMPS, UFR des Sciences de l'Homme et de l'Environnement, Université de la Réunion, 97430 Le Tampon, Ile de la Réunion, France \\ ${ }^{\mathrm{b}}$ Laboratoire CIAMS, Team RIME, UFR STAPS, Université Paris-Sud, 91440 Orsay Cedex, France
}

\begin{abstract}
A B S T R A C T
This study investigated the accuracy and reliability of four methods using force-plate data for detecting the swing heel-off ( $\mathrm{HO})$ time in gait initiation. Results of these methods were compared to those obtained by means of a reference method using a footswitch. Ten young healthy adults performed 18 forward gait initiation trials at self-selected speed and at maximal speed. Results showed that the method based on vertical impulse was the most accurate and reliable in determining $\mathrm{HO}$ in both speed conditions. The mean error obtained with this method was $-8 \pm 10 \mathrm{~ms}$ in the self-selected speed condition $(-7 \pm 10 \mathrm{~ms}$ in the maximal speed condition), with no significant effect of gait speed $(P>0.05)$. These findings suggest that this method based on force-plate data is valid and reliable for detecting $\mathrm{HO}$ in forward gait initiation in the absence of additional hardware.
\end{abstract}

\section{Introduction}

Gait initiation, which is the transition between the upright stance and the steady-state gait, is a classical paradigm to investigate the coordination between posture and movement. In this process, the swing heel-off ( $\mathrm{HO})$ time delineates the postural phase (the so-called "anticipatory postural adjustments" (APAs)) with the execution phase [1]. The exact detection of the HO event is crucial for quantifying APA features, i.e. duration and amplitude.

In most studies, force-plates are used for biomechanical analysis of gait initiation, e.g. to determine the dynamics of the centre of pressure $(\mathrm{CP})[1,2]$ and the centre of gravity (CG) [1]. Furthermore, additional hardwares such as pressure sensors or footswitches are usually used to detect the HO event [1,3]. Although these devices are effective, they may hinder natural gait development [4]. They also reduce the number of channels available for the simultaneous collection of analogue data (e.g., electromyography) [5]. An alternative method using kinematic data has been proposed [5], but the cost and the complexity of collecting measurements of motion capture systems limit its use [6].

To avoid these limitations, many studies use only force-plate data to detect HO. Several methods based on CP displacement $[2,7,8]$ or CG vertical dynamics [9] have been described in the

\footnotetext{
* Corresponding author at: Laboratoire CURAPS-DIMPS, UFR des Sciences de l'Homme et de l'Environnement, Université de la Réunion, 117 rue du Général Ailleret, 97430 Le Tampon, Ile de la Réunion, France. Tel.: +262 2625795 91; fax: +262 262579571 .

E-mail addresses: teddy.caderby@univ-reunion.fr, caderby.t@hotmail.fr (T. Caderby)
}

literature. Nevertheless, it appears from these studies that there is no clear consensus on the method to be used to detect this instant. The questions of whether the accuracy and reliability of these methods are equivalent and how they compare with the footswitch, the hardware regularly used, remain open.

The aim of this study was to assess the accuracy and reliability of four force-plate methods (three methods previously reported in the literature and a novel method) to detect $\mathrm{HO}$ and to compare their performance with a reference method using a footswitch.

\section{Methods}

Ten healthy subjects (eight males and two females, age $23 \pm 2$ years (mean \pm standard deviation [SD]), height $173 \pm 9 \mathrm{~cm}$, weight $72 \pm 11 \mathrm{~kg}$ ) were recruited for this study after being fully informed of the experimental procedure approved by the local ethics committee.

Each subject initially stood upright, barefoot and motionless on a force-plate ( $40 \mathrm{~cm} \times 60 \mathrm{~cm}$, AMTI, USA). Beforehand, a footswitch ( $25 \mathrm{~mm}$, Biometrics, France) was secured to the force-plate under the heel of the swing foot. To ensure that subjects returned to the same initial position after each trial, the foot positions were outlined on the force-plate. A second force-plate was positioned in front of the subject at a distance appropriate for the swing foot to step onto it. At the experimenter's signal, subjects initiated gait and continued walking straight ahead along a 5-m walkway. The swing leg was self-selected and remained the same throughout the experiment. Each subject performed series of 18 trials in two gait speed conditions: a self-selected speed and a maximal speed. Three practice trials were performed in each condition before the recordings. The order of the speed conditions was randomized across subjects.

The first force-plate was used to detect the HO time; the second force-plate was simply used to obtain all reaction forces during the entire gait initiation time-window (Fig. 1). The force-plate and footswitch signals, sampled to $1000 \mathrm{~Hz}$, were transmitted to an acquisition system and synchronized. Before analysis, the force-plate data were low-pass filtered at $10 \mathrm{~Hz}$ [3] with a fourthorder zero-lag Butterworth filter. The mediolateral CP coordinate (yP) was 


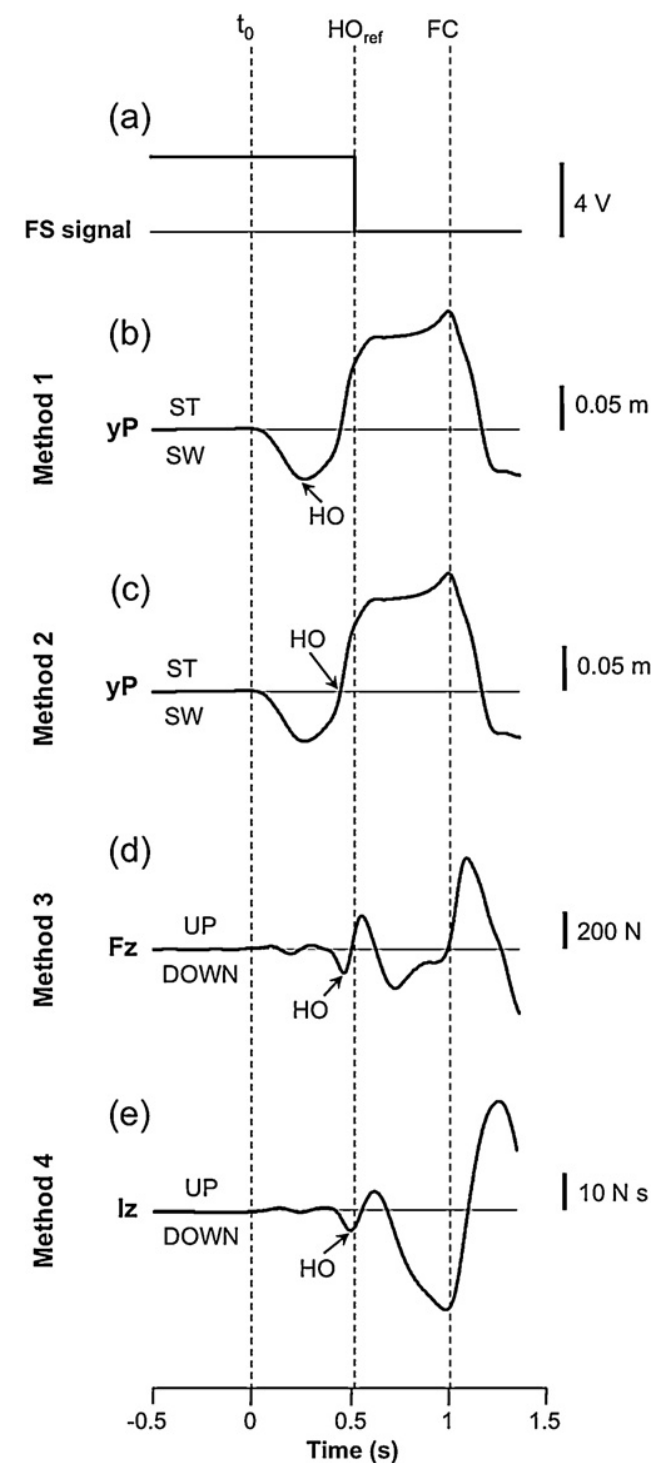

Fig. 1. Illustration of the various methods to detect the swing heel-off (HO) event. Traces are shown for one representative subject initiating gait at self-selected speed with the right leg. FS signal, yP, Fz, Iz: footswitch sensor signal, mediolateral displacement of centre of pressure, vertical ground reaction force, vertical impulse, respectively. These traces were corrected by the $250 \mathrm{~ms}$ baseline preceding the start signal. $t_{0}, \mathrm{HO}_{\text {ref, }} \mathrm{FC}$ were the onset variation of the yP trace from the baseline, reference swing heel-off instant, and swing foot-contact, respectively. F, B, ST, SW, UP and DOWN indicate forward, backward, stance limb, swing limb, upward and downward respectively. The footswitch sensor signal was used to identify the reference $\mathrm{HO}$ time $\left(\mathrm{HO}_{\text {ref }}\right)$ (a). Method 1 predicted $\mathrm{HO}$ when yP reached its maximal value towards the swing limb (b). Method 2 predicted HO when yP changed sign (the first frame was considered) (c). Method 3 identified $\mathrm{HO}$ when Fz peaked downwards (peak preceding the last downward peak) (d). Method 4 identified HO when Iz peaked downwards before the last (usually maximal) downward peak (e).

calculated from force-plate data and was corrected by the $250 \mathrm{~ms}$ baseline preceding the start signal [3]. Vertical impulse (Iz) was calculated by integrating (trapezoidal rule) the vertical ground-reaction force (Fz), after weight correction (Fig. 1). Calculation was performed with integration constant equal to zero, i.e. initial impulse null [1].

The reference $\mathrm{HO}$ time $\left(\mathrm{HO}_{\text {ref }}\right)$ was determined from the footswitch signal, as shown in Fig. 1(a). Four methods based on force-plate data were used to estimate the $\mathrm{HO}$ time. For each method, the HO event was detected manually by two experimented raters as illustrated in Fig. 1:

- Method 1 detected HO when yP first peaked towards the swing limb [2,8] (b). - Method 2 identified HO when yP changed sign [7] (c).

- Method 3 predicted HO when Fz peaked downwards (based on [9]) (d).

- Method 4 was custom-designed and detected HO when Iz peaked downwards (e).
Table 1

The means and standard deviations (SD) of the differences between the instants of swing heel-off (HO) predicted by the various methods and the reference timing identified from the footswitch sensor, expressed in milliseconds (ms) and as a percentage of APA duration (\%dAPA).

\begin{tabular}{ccccc}
\hline & Method 1 & Method 2 & Method 3 & Method 4 \\
\hline $\begin{array}{c}\text { Self-selected speed } \\
\text { Mean error } \pm \text { SD (ms) }\end{array}$ & $-243 \pm 86^{\mathrm{a}}$ & $-77 \pm 42$ & $-43 \pm 15$ & $-8 \pm 10$ \\
Mean error \pm SD (\%dAPA) & $-40 \pm 13^{\mathrm{b}}$ & $-13 \pm 7^{\mathrm{a}}$ & $-7 \pm 3^{\mathrm{a}}$ & $-1 \pm 2$ \\
Maximal speed & & & & \\
Mean error \pm SD (ms) & $-215 \pm 83$ & $-70 \pm 37$ & $-41 \pm 13$ & $-7 \pm 10$ \\
Mean error \pm SD (\%dAPA) & $-34 \pm 13$ & $-11 \pm 6$ & $-6 \pm 2$ & $-1 \pm 2$ \\
\hline
\end{tabular}

Method 1: algorithm identifying $\mathrm{HO}$ when the mediolateral displacement of the $\mathrm{CP}$ first peaked towards the swing limb. Method 2: algorithm identifying HO when the mediolateral displacement of the CP changed sign. Method 3: algorithm using the vertical ground reaction force. Method 4: algorithm using the vertical impulse.

a Significant difference self-selected versus maximal speed, $P<0.05$.

b Significant difference self-selected versus maximal speed, $P<0.01$.

The mean and standard deviation of the differences (errors) between the HO instant estimated by each of the four force-plate methods and that obtained by the footswitch method were calculated to assess the accuracy and reliability of these methods [10]. A positive value indicated that the $\mathrm{HO}$ time was delayed compared with the reference method while a negative value indicated it was early. The differences were expressed in milliseconds and as a percentage of APA duration (dAPA). APA duration was defined as the delay between the first dynamic phenomena $\left(t_{0}\right)$ and $\mathrm{HO}$ time [1]. After checking for data normality with Kolmogorov-Smirnov test, Student's $t$-tests for paired samples were used to assess the effect of gait speed on the error made with each method. Threshold for significant difference was $P<0.05$.

\section{Results}

Table 1 shows the differences (mean \pm SD) between the instants of HO predicted by each force-plate method and the reference timing identified from the footswitch sensor. The errors distribution for each method is illustrated as histogram in Fig. 2. On average, the methods detected $\mathrm{HO}$ earlier than the reference method (Table 1 ). In both gait speed conditions, Method 4 provided the smallest mean error and SD among the tested methods (Table 1 ). The mean error on HO detection obtained with this method was $-8 \pm 10 \mathrm{~ms}$ in the self-selected speed condition and $-7 \pm 10 \mathrm{~ms}$ in the maximal speed condition, with no significant difference across conditions $(P>0.05)$. Note that this error corresponded to solely $-1 \pm 2 \%$ of APA duration. In absolute terms, the errors of this method were less than $30 \mathrm{~ms}$ in $96 \%$ of trials in the self-selected speed condition (97\% in the maximal speed condition; Fig. $2 \mathrm{~g}$ and $\mathrm{h}$ ).

In contrast to Method 4, statistical analysis revealed that the mean error (expressed in percentage of APA duration) significantly decreased with gait speed for Method $1(t=-4.562, P<0.01)$, Method $2(t=-2.762, P<0.05)$ and Method $3(t=-3.250, P<0.05)$. When expressed in milliseconds, it significantly decreased with gait speed only for Method $1(t=-2.974, P<0.05)$.

\section{Discussion}

Globally, the methods detected HO earlier than the reference method. Some authors [6] had already reported this trend for Method 2. In the current study, Method 4 presented the smallest error and SD whatever the gait speed, indicating that this method was the most accurate and reliable method to detect HO in those tested. The errors of this method were smaller than $30 \mathrm{~ms}$ in $96 \%$ of trials in the self-selected speed condition (97\% in the maximal speed condition). It is noteworthy that these results are slightly better than those found using a kinematic method where errors are less than $30 \mathrm{~ms}$ in over $92.5 \%$ of the cases [5].

The high reliability and accuracy of Method 4 might be ascribed to a causal link between the HO time and the marker used to detect 

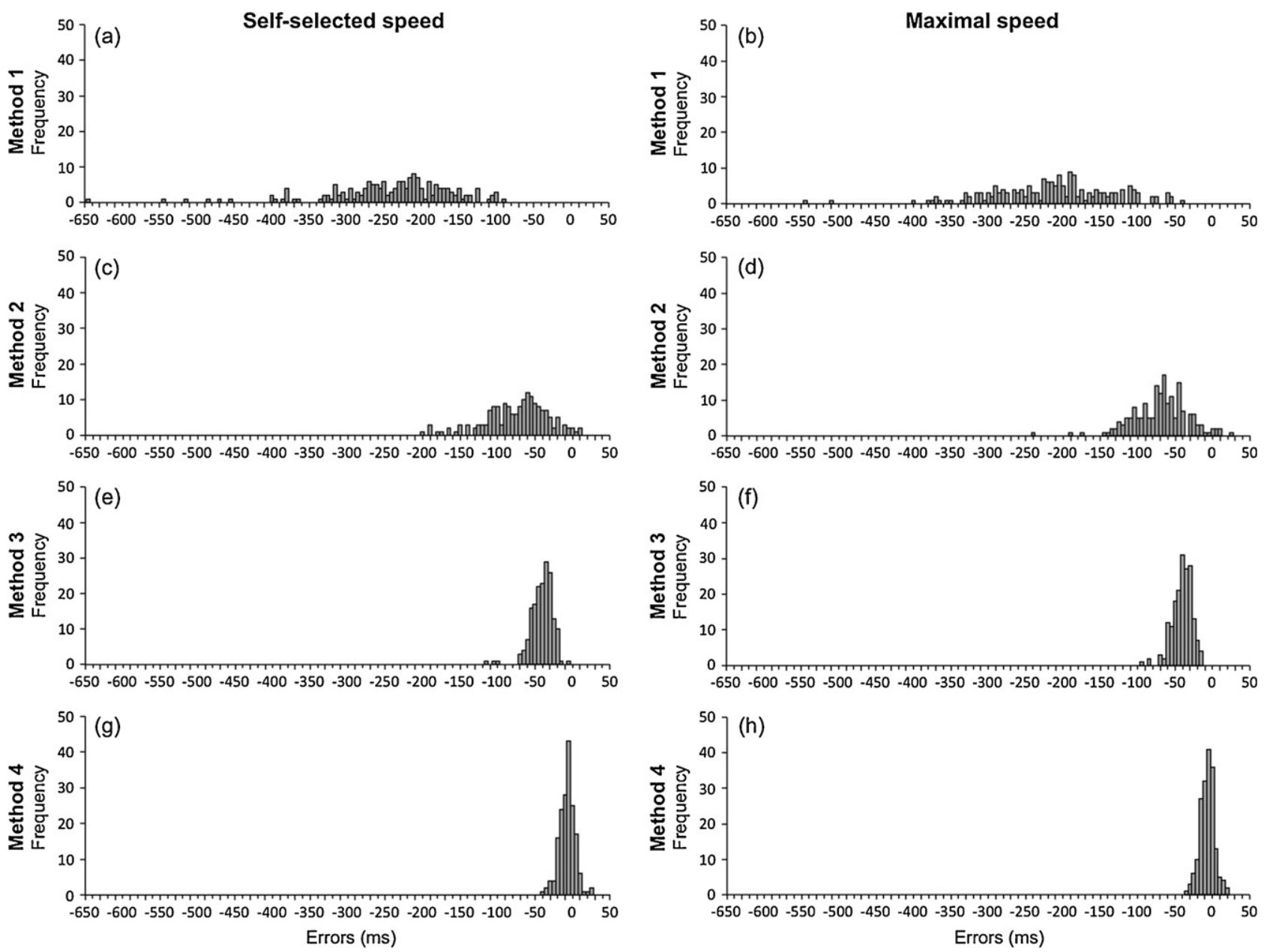

Fig. 2. Frequency distribution of errors for each method in the conditions of self-selected speed (left column) and maximal speed (right column).

this time (peak of downward Iz). HO is indeed associated with swing leg rise, which could act to attenuate the fall of the CG (classically described using the CG vertical velocity [11]) during the subsequent execution phase. In other words, it could be that the reversal of the negative vertical impulse might be ascribed to an effect of the swing leg rise associated with HO. The fact that the accuracy and reliability of Method 4 are speed-independent (in contrast to the other methods) is in agreement with this hypothesis.

Results further showed that SD values ranged from $10 \mathrm{~ms}$ (i.e. $2 \%$ of APA duration) with Method 4 to $86 \mathrm{~ms}$ (13\% of APA duration) with Method 1 (Table 1). This range of SD values suggests that the reliability of the HO time measure (and therefore the reliability of APA spatio-temporal features) may strongly depend on the method used. Future studies on APA in gait initiation should therefore be cautious with regard to the method used to detect HO. Further investigation is also required to determine whether the present results apply to populations with gait disorders.

\section{Conclusion}

The results showed that the method based on vertical impulse was the most accurate and reliable for detecting HO time from force-plate data. In the absence of additional hardware, this method constitutes an attractive alternative to detect the swing heel-off time in forward gait initiation.

\section{Acknowledgements}

This work was supported by a grant from the University of La Reunion. The authors wish to thank Mrs. Kytte Tameire for his technical assistance.

\section{Conflict of interest statement}

None of the authors have financial or other conflicts of interest in regards to this research.

\section{References}

[1] Brenière $Y$, Do MC, Bouisset $S$. Are dynamic phenomena prior to stepping essential to walking. Journal of Motor Behavior 1987;19:62-76.

[2] Halliday SE, Winter DA, Frank JS, Patla AE, Prince F. The initiation of gait in young, elderly, and Parkinson's disease subjects. Gait and Posture 1998;8:8-14.

[3] Corbeil P, Anaka E. Combined effects of speed and directional change on postural adjustments during gait initiation. Journal of Electromyography and Kinesiology 2011;21:734-41.

[4] Ghoussayni S, Stevens C, Durham S, Ewins D. Assessment and validation of a simple automated method for the detection of gait events and intervals. Gait and Posture 2004;20:266-72.

[5] Mickelborough J, van der Linden ML, Richards J, Ennos AR. Validity and reliability of a kinematic protocol for determining foot contact events. Gait and Posture 2000;11:32-7.

[6] Martinez-Mendez R, Sekine M, Tamura T. Detection of anticipatory postural adjustments prior to gait initiation using inertial wearable sensors. Journal of NeuroEngineering and Rehabilitation 2011;8:17.

[7] Yiou E, Do MC. Effects of medio-lateral postural perturbation induced by voluntary arm raising on the biomechanical organization of rapid step initiation. Motor Control 2011;15:507-24. 
[8] Rogers MW, Hedman LD, Johnson ME, Martinez KM, Mille ML. Triggering of protective stepping for the control of human balance: age and contextual dependence. Brain Research Cognitive Brain Research 2003;16:192-8.

[9] Ledebt A, Bril B, Breniere Y. The build-up of anticipatory behaviour. An analysis of the development of gait initiation in children. Experimental Brain Research 1998;120:9-17.
[10] Leitch J, Stebbins J, Paolini G, Zavatsky AB. Identifying gait events without a force plate during running: a comparison of methods. Gait and Posture 2011;33:130-2

[11] Welter ML, Do MC, Chastan N, Torny F, Bloch F, du Montcel ST, et al. Control of vertical components of gait during initiation of walking in normal adults and patients with progressive supranuclear palsy. Gait and Posture 2007;26:393-9. 